\title{
How Do Students Adapt in Response to Academic Failure?
}

\author{
Rola Ajjawi \\ Deakin University, Melbourne, Australia \\ David Boud \\ Deakin University, Melbourne, Australia \\ Nadine Zacharias \\ Swinburne University of Technology, Melbourne, Australia \\ Mary Dracup \\ Deakin University, Melbourne, Australia \\ Sue Bennett \\ University of Wollongong, Wollongong, Australia
}

\begin{abstract}
Ensuring student success has long been on the research agenda in higher education. In this study, we seek to understand if the changes students make in light of academic failure are consistent with this literature. Little is known about students who fail but subsequently persist in their studies. Through an online survey with students who had failed and persisted, we identified drivers for persistence and how students adapted in response to academic failure. Thematic analysis showed that the majority of students did not seek institutional support following academic failure but they did seek support from peers, family and friends. These adaptations occurred at multiple levels: dispositional, situational and institutional. Drivers reported were internal (desire to complete) and external (desire to meet expectations). Although the majority of our students showed positive adaptations following academic failure, a significant portion reported no changes to their academic strategies. The paper poses the question of how students who fail can be better supported to continue successfully.
\end{abstract}

Keywords: Academic failure; persistence; self-efficacy; attrition; sense of belonging; undergraduate.

\section{Introduction}

Academic failure is relatively common in higher education. Our own analysis of 2016-17 institutional data from a large, comprehensive Australian university showed that the incidence of academic failure varied across courses with roughly $40 \%$ of students failing one or more academic units during their degree. Importantly, academic failure contributed a four-fold increase to the risk of course attrition compared to students who did not fail a unit of study (Ajjawi, Dracup, Zacharias, Bennett, \& Boud, 2019). Approximately $70 \%$ of those who failed persisted with their studies, while $30 \%$ dropped out and $58 \%$ of those who failed one unit subsequently failed more. Academic failure is often attributed to multiple factors, which suggests that multiple strategies are required for successful course completion following a failure. Furthermore, the diversification of the student body including "the growing realities of non-linear student pathways, diverse student cohorts, and increasingly partial, part-time, deferred and liminal enrolment status" attunes us to the need for flexible and tailored/individualised support strategies

This work is licensed under a Creative Commons Attribution 4.0 International Licence. As an open access journal, articles are free to use with proper attribution. ISSN: 2205-0795 
(Harvey, Szalkowicz, \& Luckman, 2017, p. 7). Given that the majority of students, who fail do persist (Ajjawi et al., 2019), understanding the strategies they use to overcome academic failure might help us to better support students who fail, in all their diversity. In this paper, we examine the responses of students who fail and persist, to identify what drives them to continue, the support strategies they seek and how they adapt.

\section{Literature review}

A strong literature base has explored enablers of success and retention from the perspective of institutions and students (Bowles \& Brindle, 2017; Carroll, Ng, \& Birch, 2009; Kahu \& Nelson, 2018; Yorke \& Longden, 2004; Zepke, Leach, \& Butler, 2011). Exploring this literature informs us that enablers to success are needed at dispositional, situational and institutional levels (Bowles \& Brindle, 2017). The dispositional factors are an individual student's characteristics such as self-confidence, attitudes and beliefs. Situational factors refer to "life circumstances" including health, employment and family responsibilities. Institutional factors are influenced by the educational institution and may include institutional procedures, policies and structures. Zepke et al. (2011) found that self-organisation and the support of family and friends had a strong influence on success. Collectively, the literature highlights that enablers of success are complex and multi-dimensional, and play out differently in different contexts (Coates \& Matthews, 2018).

Although success and retention (and course withdrawal) are widely researched and discussed, few studies focus on students' experiences following academic failure. What we do know is that students report negative emotional feelings towards themselves including a loss of confidence in their own abilities (Ajjawi et al., 2019; Jevons \& Lindsay, 2018). Yet, self-efficacy is an important pillar of Kahu and Nelson's (2018) as well as Tinto's $(2012,2017)$ persistence model. Tinto argues that persistence: "is the quality that allows someone to continue in pursuit of a goal even when challenges arise. A student has to want to persist to degree completion in order to expend considerable effort to do so" (Tinto, 2017, p. 2). Tinto (2017) proposes three key motivators for students to persist when faced with academic struggles: self-efficacy, a sense of belonging and the revaluing of the curriculum. A student's response to the challenges, stressors and risk factors presented over the course of their university degree will determine the value and success of their experience and future learning experiences. Their adaptations following failure may relate to mobilisation of self-efficacy, feelings of belonging and a (re)valuing of the curriculum which might enable them to succeed. What is original about our current research is that it explores diverse students' strategies to persist following actual experiences of academic failure.

The current paper answers the following specific research questions:

1) What are the drivers for persisting following academic failure?

2) How do students adapt in response to academic failure?

\section{Methods}

This paper focuses on one aspect of a larger study exploring academic failure and persistence in higher education. In particular, we report on findings of an online survey of students who failed at least one unit of study in 2016 and persisted with their studies as of census date Semester 1/2017. Academic failure is defined as having been assigned a fail grade for a unit of study. Our previous paper (Ajjawi et al., 2019) reported on the institutional data and factors influencing academic failure, whilst this paper reports on student adaptations and sources of support in response to failure.

\section{Participants and Courses Included in the Research}

The study occurred in a large Australian university with diverse student cohorts where $24 \%$ of students are external (studying fully online), and $37 \%$ mature age ( $>24$ years of age). Participants were recruited from professionally oriented undergraduate courses with a range of minimum entrance scores (Education, Civil Engineering, Nursing and Commerce).

Course administration staff emailed invitations to the online survey to 2260 students identified as having failed at least one academic unit in Semester 1 and/or Semester 22016 and re-enrolled in Semester 12017 (as at census date). Of these, 186 students (response rate $=8.2 \%$ ) completed the survey. The low response rate is, possibly due to this being a disaffected group that is difficult to research. Students from each of the four courses were represented in the survey responses - from Education 
9.4\% $(\mathrm{n}=25)$ of eligible students took part, $7.5 \%(\mathrm{n}=7)$ from Civil Engineering, $19 \%(\mathrm{n}=73)$ from Nursing and 5.3\% $(\mathrm{n}=81)$ from Commerce. Of the 175 students who completed the demographic questions, $69.7 \%$ of respondents were female ( $\mathrm{n}=124)$ and $23 \%$ studying part time $(\mathrm{n}=40)$. International students comprised $25 \%$ of the sample $(\mathrm{n}=44)$, while external enrolment was $12.4 \%(\mathrm{n}=22)$.

\section{Online Survey}

The research team developed the survey questions, informed by the literature (Bowles \& Brindle, 2017; Tinto, 2012, 2017). The survey was piloted with seven students, leading to minor revisions to format and wording. The majority of questions were open-ended in order to elicit students' explanations and experiences.

After cleaning the spreadsheet data, to remove empty cells, we sorted the survey responses by course, and then divided course responses among team members to read and code using a shared NVivo 11 project. The research team coded each individual question response according to an initial theoretical framework of nodes and sub-nodes drawn from the literature (principally Bowles and Brindle's [2017] categorisation of dispositional, situational and institutional factors), grouping students' responses after failing a unit into sources of support and what was learned. We shared reflections on the developing coding framework as we coded, and added or merged nodes as needed. The coding framework was continually refined during the coding process to accommodate all data.

Once coding was complete, we downloaded and divided the major nodes amongst ourselves and worked in pairs to prepare and cross-check summaries of each of the sub-nodes. Once pairs had agreed on the meanings of each sub-node summary, they were compiled into a thematic framework chart (Ritchie \& Spencer, 2002), from which we have drawn the findings below.

\section{Results}

\section{Research question 1: What are the drivers for persisting following academic failure?}

Students reported multiple drivers for persisting. Determination to finish the degree and to achieve academic and career goals was the primary motivation. Students regularly commented on wanting to become professionals in order to fulfil internal needs (e.g. "passion", "interest") and to provide a better life or future prospects for themselves and/or their families. Thus, the situation of being in the right course for them helped to spur them on.

Some students were determined not to give up, highlighting an internal drive to persist: e.g. "I want to finish because I never leave anything undone." Others were "matter of fact" about academic failure, refusing to be defined by it, explaining that "one bad result won't derail me" or "one bad result won't ruin my whole degree, apart from the annoyance of repeating. I'm not too worried about it." And some characterised themselves as resilient due to overcoming adversity in the past: "Slump of depression but [I'm] used to fighting: something else I had to overcome" or "I suffer from MS so I'm used to overcoming bumps in the road."

Several students mentioned the stage of their degree being relevant to them persisting. This was related to them not wanting to give up late in their degree and so waste the time, money and effort already invested. The effort already spent enabled them to reframe the academic failure as a small bump, e.g. "I only have five units left until my degree is finished. I have studied for the last six years and am not giving up that easily or wasting my study." Similarly, failing one unit relative to the ones already completed enabled one student to downplay the failure and attribute it to "bad luck" rather than taking it personally, e.g. "I was already halfway, there was no way I was going to give up just because of one subject. I knew it was not a matter of me being incapable it was just bad luck that I was sick."

Family and friends played a key role in persistence, e.g. "They were supportive and I knew I could complete the units, and this has made me more dedicated the second time around." Students mentioned continuing because of a desire to make their families proud of them and feeling more dedicated to their studies after receiving their help. However, parental expectations were also mentioned as a source of stress, with feelings of guilt at being a burden or a disappointment. These mixed results suggest that interpersonal relationships can provide positive support networks that enable students to continue their studies, but this is not always the experience of students who persist after failure. 


\section{Research question 2: How do students adapt in response to academic failure?}

About 30\% ( $\mathrm{n}=52$ ) of students reported not making any adaptations in response to academic failure. Those who did make adaptations described varied responses to the experience of academic failure including at the dispositional level (e.g. changing study behaviours or goal planning); situational level (e.g. learning to ask questions in class or seeking peer-study opportunities); and institutional level (e.g. seeking institutional support or considering alternative course pathways). In many cases students drew on multiple strategies and supports, making their responses and adaptations highly individualised and idiosyncratic. There was no universal approach to recovering from academic failure, and experiences of obtaining support were mixed.

\section{Dispositional Adaptations}

The majority of dispositional adaptations related to individual improvements in study habits including: time management, studying harder, attending class, asking questions of teachers, being better prepared and being more proactive. Students reported prioritising their time to make more space for study, e.g. "Studies has been a second priority to me because I was running a business and [I was] also a footballer at the time. I now have dedicated more time to finishing my degree."

Students recognised the need to be more proactive with their study and reported better self-regulatory behaviours including goal setting and monitoring progress. They cited spending more time on campus, in class and doing study:

I started using the university's assignment calendar to help me plan out my research, writing and draft skills. I also set up timetables differently so I had the opportunity to do the class work a few nights before, then study that subject the night before class so I understood the topics, which has helped my exam studies as well.

I make sure I check the criteria thoroughly, and ensure I don't miss any important information. I mark my assignment due dates, exams, and/or clinical placements on the yearly calendar provided to me by [institution] Study Support staff.

\section{Situational Adaptations}

The majority of respondents (58\%, $\mathrm{n}=104)$ sought help from family and friends. Positive support networks of family and friends played a key role in helping students gain perspective and in rebuilding students' confidence and self-esteem following experiences of academic failure. Family and friends offered emotional support because they listened, advised, provided empathy, encouraged and motivated students to continue with their studies:

My mum and family. They reassured me it wasn't the end of the world and that we all have these things happen in life, but they kept me motivated to keep going and I realised it's what I want to do in life and I wanted to complete the course.

Several students contrasted the support of friends to the lack of support offered by the university, e.g. "It helped me keep my calm through the situation. University is so impersonal, so it was good to have the support of my family and friends as there was nothing I knew of or provided to me by the University." Family and friends also offered practical help (e.g. provided food).

However, a small number of students were sceptical of the support offered by family:

There can be a lot of pressure from family members to do well and sometimes they contradict what they previously said. That can be really frustrating. Or when they instruct you on what to do but they don't really go through with what they said and, or they don't do anything that is actually going to help you.

Family and friends also provided academic support in helping students to improve their understanding of the unit context, better understand assessment requirements and improve study skills, e.g. "I find they often can look at my questions from a different perspective and provide me a new angle with which to look at problems from." Several commented on family and friends helping with institutional processes, such as providing assistance to write appeals.

Other students sought study buddies, these informal networks of peer support were an additional situational support, to mixed effect:

The maths in the unit was very hard to learn, especially studying online. The second time around I had a study buddy and a tutor which helped immensely. I did well in the two written assignments but failed in the exam. 


\section{Institutional Adaptations}

In explaining the changes they made in response to their academic failure, the majority of respondents in our survey (58\%, $\mathrm{n}=108)$ revealed that they did not seek help from institutional support services. Those who did seek institutional help ( $42 \%$, $\mathrm{n}=77$ ) accessed a wide range of support services including unit chairs, course advisors, learning and writing advisors, international officers, counsellors, doctors, disability resource centre staff, librarians, the student union and the Indigenous Centre.

Students most frequently sought help from course advisors and they mostly found these advisors to be helpful in supporting them to identify new pathways through their degree. Course advisors, being familiar with the course, were seen as being able to offer relevant and specific advice, e.g. "Preferred seeing the course advisors as they all by the end of it knew who I am, and were able to help me thoroughly in every situation I faced." Students reported being able to re-plan their academic pathways, think about reducing academic load and consider different electives, e.g. "Very good as they helped me map out my course and recommended enrolling in only three units each semester to ease the work load."

A few students commented that course advisors also offered emotional support, and students learned that academic failure is not uncommon, e.g. "The course advisor was very helpful and assured me that others do in fact fail the same subject, which made me feel more comfortable with failing a subject as I had not failed subjects previously in school."

Of the central institutional support services available, students most frequently cited seeking counselling services, followed by psychologists. These support services received mixed reviews, with some students reporting they felt that the sessions had not helped, whilst others found them valuable in helping them address personal issues at the time or anxiety and stress related to exams, e.g. "Counselling was great. She helped me to keep calm and helped me to see that I needed a break. The student services helped me sort out my units for the future and helped the transition back to uni to be as easy as possible". Counsellors also played a part in diagnosing conditions that may have affected learning:

Counsellor was helpful in working through grief after loss of a close friend to cancer. Discussed a number of ways of staying on top of my life, some of which helped and others which didn't. Although not explicitly suggested, discussions with the counsellor were part of what prompted me to get assessed (and subsequently diagnosed as having ADHD).

Fewer students also mentioned academic study skills support to inconsistent effects.

\section{Discussion}

Overall, the results of our study show that the students who responded to the survey were driven by internal and external motivators, such as their own determination to succeed and their desire to achieve academic and career goals. Meeting the expectations of family and friends was a positive external motivator for some, but not experienced as motivating by others. Research has shown that having a clear direction and sense of purpose correlates with persistence and adjusting to university (Krause, Hartley, James, \& McInnis, 2005). Students' vocational goals have been found to influence their persistence (Lizzio \& Wilson, 2010) and is consistent with our professionally oriented degrees sampled.

Most of our respondents indicated they made adaptations to their approach in light of their experiences of academic failure. Dispositional strategies were most common, particularly changing behaviours and setting goals that focused on successful study. It is striking that even students who attributed their failure mainly to external causes, rather than their own actions, responded by adjusting their own behaviour. This suggests that persistence is supported by taking control of the situation oneself. Seeking help from others was also prominent and this took the form of situational strategies (engaging in positive interpersonal relationships with family and friends) and institutional strategies (seeking course advice from academic staff). For students with complex needs, drawing on multiple supports seemed critical to them continuing with their studies.

The students also engaged with central university support services, particularly through general practitioners, counsellors and psychologists to help them develop coping strategies. Responses indicated that seeking professional support occurred either through self-referral or following advice from the academic progress committee or the student union. Worryingly, the majority of students did not seek institutional support despite high reports of mental health issues contributing to their academic failure (Ajjawi et al., 2019). It is not clear why they did not pursue such help, although this is likely to be multifactorial. Reasons for this may include not being aware of available services, fear of stigma, shame or embarrassment. Further, research in to student well-being suggests that students want academic and emotional support from their academic staff, those who know them 
personally and who know the course (Baik, Larcombe, \& Brooker, 2019). Our data is mostly silent about the role of academics and teaching staff in supporting students following failure. Perhaps this is why valuing of the curriculum was not a response reported by any of our students. Instead, they spoke of repeating units as another hurdle to be overcome in an instrumental way. Therefore, only two of Tinto's three pillars come into play for student persistence in our study: mobilising self-efficacy and relatedness through peers, family and friends. Without students relating to teachers and revaluing the curriculum they continue to be at risk of disengaging from their studies and potentially further failure.

Another lens from which the work could be viewed is resilience. While failure can trigger changes to life trajectories, despair or at least disappointment; for some students to "fail" may be a positive learning experience, to signal that they need to change their habits (Peelo \& Wareham, 2002, p. 3). We had avoided any pre-conceived notions about resilience coming into this project. Resilience has garnered attention recently with the rise of incidence of stress and mental health problems in university students (Ibrahim, Kelly, Adams, \& Glazebrook, 2013; Macaskill, 2013; Orygen, 2017). Resilience, is defined as "a set of attitudes and behaviours which are associated with an individual's ability to bounce back and to adapt in the face of risk and stress" (Holdsworth, Turner, \& Scott-Young, 2018, p. 1). It is dynamic and can be developed with life experience. Indeed based on the definition by Holdsworth and colleagues, it could be said that many of our students exhibited/activated resilience strategies in response to academic failure where they sought friends and family to help them develop perspective, visited counsellors, GPs and psychologist in aiming to be healthy and leaned into their networks at university and outside for social and academic support. Our caution is that we as academics absolve ourselves of responsibility through an individualistic rhetoric of resilience, where students are seen to have: "the willpower and the personal resources to overcome any obstacle. You just need the ambition and then the determination. The unspoken corollary is that if you are not achieving some identifiably ambitious success, you are deficient in willpower and resolve." (Nelson, 2018, p. 1059).

Implications of this work point in different directions and are in tension. Students benefited from the agency needed to navigate their adaptations as necessary to their own situation, to mobilise resilience strategies and to feel a sense of accomplishment from doing so. Yet we also know, that $30 \%$ of our respondents reported making no adaptations (likely a conservative estimate due to the response rate). Students who fail are more likely to fail again and their risk of dropping out of their course increases four-fold after failing their first unit, not to mention that their self-efficacy is likely dampened (Ajjawi et al., 2019) and so relying on their own strategies to navigate a path to success alone is insufficient. Nelson (2018) reminds us that as academics we need to resist passing onto students a false discourse of empowerment where success is conceptualised as something that is totally within their control. However, if remediation and/or support strategies are mandated by the institution, we risk reducing students' autonomy and therefore their internal motivation (Ryan \& Deci, 2000). This is a delicate balance where shared understanding through dialogue and shared responsibility becomes necessary.

Kahu and Nelson (2018) note that student success requires student-institutional partnerships - shared responsibility - to optimise four psychosocial constructs, self-efficacy, belonging, emotional regulation and well-being in the educational interface. This requires that academics or academic mentors work with the students based on their needs to activate resilience strategies and de-stigmatise academic failure and help-seeking. A more sophisticated approach by the institution is needed. Tailoring interventions to specific students would take account of dispositional, situational and institutional factors, support might be light-touch if a student reports positive adaptations, then escalating if the frequency of failure increases. Developing support networks are a key attribute linked to resilience (Holdsworth et al., 2018), our research shows that these networks can be broad encompassing peers, family and friends within and outside the university sphere. Emotional support is also crucial to helping students recover from failure and to make sense of the experience. Such overt attempts at sharing responsibility with staff might help students to revalue the curriculum.

Future research points towards longitudinal research to examine the success or otherwise of the student-led adaptations following academic failure especially given the high repeat failure rates and its relation to attrition. A remaining question illuminated by this research is about the $30 \%$ of students who failed, chose to persist yet reported no adaptations in response to their experience. It would be important to understand why they chose not to seek help or modify their actions and how this approach influenced their success in the longer term. It is also relevant to consider what the university's responsibility is in more actively supporting students who might be floundering, not knowing what to do in the face of failure and potentially repeated failure. Given that analysis of failure rates suggests various types of supports for different types of students would be helpful (Wimshurst \& Allard, 2008), future research would seek to explore whether particular student characteristics elicited particular adaptation responses to academic failure. 


\section{Limitations}

The survey's response rate was about $8 \%$, which is lower than we had hoped. Although the majority of students who responded to our survey reported making adaptations, the longer term success of such strategies is not known. It is likely that those who responded to our survey were more committed to their study, therefore those making positive adaptations are overreported.

\section{Conclusion}

Academic failure is a significant event in a student's academic journey that needs to be acted on by the student and the institution. Our study found that the majority of students proactively sought support and changed as a result of failure. Adaptations that students made were mostly in terms of changing their own study habits and prioritisation, as well as seeking support from peers, family and friends. Less utilised institutional support services, whilst support from teaching staff was limited. Many of the students who persisted following academic failure showed a range of resilience strategies, determination and agency, although some reported making no changes. These responses can be interpreted as leading to improved self-efficacy and some relatedness but not a revaluing of the curriculum. The findings challenge us to consider how educational institutions can provide better support for students who fail without inadvertently undermining their own coping strategies.

\section{References}

Ajjawi, R., Dracup, M., Zacharias, N., Bennett, S., \& Boud, D. (2019). Persisting students' explanations of and emotional responses to academic failure. Higher Education Research \& Development. https://doi.org/10.1080/07294360.2019.1664999

Baik, C., Larcombe, W., \& Brooker, A. (2019). How universities can enhance student mental wellbeing: The student perspective. Higher Education Research \& Development, 38(4), 674-687. https://doi.org/10.1080/07294360.2019.1576596

Bowles, T. V., \& Brindle, K. A. (2017). Identifying facilitating factors and barriers to improving student retention rates in tertiary teaching courses: A systematic review. Higher Education Research \& Development, 36(5), 903-919. https://doi.org/10.1080/07294360.2016.1264927

Carroll, D., Ng, E., \& Birch, D. (2009). Retention and progression of postgraduate business students: An Australian perspective. Open Learning: The Journal of Open, Distance and e-Learning, 24(3), 197-209. https://doi.org/10.1080/02680510903201599

Coates, H., \& Matthews, K. E. (2018). Frontier perspectives and insights into higher education student success. Higher Education Research \& Development, 37(5), 903-907. https://doi.org/10.1080/07294360.2018.1474539

Harvey, A., Szalkowicz, G., \& Luckman, M. (2017). The re-recruitment of students who have withdrawn from Australian higher education. https://www.voced.edu.au/content/ngv\%3A75671

Holdsworth, S., Turner, M., \& Scott-Young, C. M. (2018). ... Not drowning, waving. Resilience and university: A student perspective. Studies in Higher Education, 43(11), 1837-1853. https://doi.org/10.1080/03075079.2017.1284193

Ibrahim, A. K., Kelly, S. J., Adams, C. E., \& Glazebrook, C. (2013). A systematic review of studies of depression prevalence in university students. Journal of Psychiatric Research, 47(3), 391-400. https://doi.org/10.1016/j.jpsychires.2012.11.015

Jevons, C., \& Lindsay, S. (2018). The middle years slump: Addressing student-reported barriers to academic progress. Higher Education Research \& Development, 37(6), 1156-1170. https://doi.org/10.1080/07294360.2018.1462305

Kahu, E. R., \& Nelson, K. (2018). Student engagement in the educational interface: Understanding the mechanisms of student success. Higher Education Research \& Development, 37(1), 58-71. https://doi.org/10.1080/07294360.2017.1344197

Krause, K., Hartley, R., James, R., \& McInnis, C. (2005). The First Year Experience in Australian Universities: Findings from a Decade of National Studies. Australian Department of Education Science and Training. Canberra.

Lizzio, A., \& Wilson, K. (2010, 27-30 June). Strengthening commencing students' sense of purpose: Integrating theory and practice. [Paper presentation] 13th Pacific Rim First Year in Higher Education Conference, Adelaide, Australia.

Macaskill, A. (2013). The mental health of university students in the United Kingdom. British Journal of Guidance \& Counselling, 41(4), 426-441. https://doi.org/10.1080/03069885.2012.743110

Nelson, R. (2018). Failing with student success: The hidden role of bad luck and false empowerment. Higher Education Research \& Development, 37(5), 1050-1061. https://doi.org/10.1080/07294360.2018.1462306 
Orygen (2017). Under the radar: The mental health of Australian university students. https://www.orygen.org.au/Policy/Policy-Reports/Under-the-radar

Peelo, M., \& Wareham, T. (2002). Failing students in higher education. Society for Research into Higher Education \& Open University Press.

Ritchie, J., \& Spencer, L. (2002). Qualitative data analysis for applied policy research. In A. Brayman \& R. G. Burgess (Eds.), Analyzing qualitative data (pp. 187-208). Routledge.

Ryan, R. M., \& Deci, E. L. (2000). Intrinsic and Extrinsic Motivations: Classic Definitions and New Directions. Contemporary Educational Psychology, 25, 54-67. https://doi.org/10.1006/ceps.1999.1020

Tinto, V. (2012). Completing college: Rethinking institutional action. University of Chicago Press.

Tinto, V. (2017). Reflections on Student Persistence. Student Success, 8(2), 1-8. https://doi.org/10.5204/ssj.v8i2.376

Wimshurst, K., \& Allard, T. (2008). Personal and institutional characteristics of student failure. Assessment \& Evaluation in Higher Education, 33(6), 687-698. https://doi.org/10.1080/02602930701772911

Yorke, M., \& Longden, B. (2004). Theory: a multiplicity of perspectives. In M. Yorke \& B. Longden (Eds.), Retention and Student Success in Higher Education (pp. 75-88). Society for Research into Higher Education \& Open University Press.

Zepke, N., Leach, L., \& Butler, P. (2011). Non-institutional influences and student perceptions of success. Studies in Higher Education, 36(2), 227-242. https://doi.org/10.1080/03075070903545074

\section{Please cite this article as:}

Ajjawi, R., Boud, D., Zacharias, N., Dracup, M., \& Bennett, S. (2019). How do students adapt in response to academic failure? Student Success, 10(3), 84-91. https://doi.org/10.5204/ssj.v10i3.1403

This article has been peer reviewed and accepted for publication in Student Success. Please see the Editorial Policies under the 'About' section of the Journal website for further information.

Student Success: A journal exploring the experiences of students in tertiary education

(c) () free to use with proper attribution. ISSN: 2205-0795 